\title{
ANNOUNCEMENT \\ Fellowship In Reconstructive and Functional Urology
}

SOUTHERN ALBERTA INSTITUTEOF UROLOGY

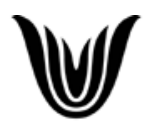

vesia

[ ALBERTA BLADDER CENTRE ]

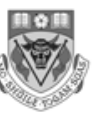

FACULTY OF | UNIVERSITY OF MEDICINE CALGARY
Offered by vesia [ALBERTA BLADDER CENTRE] and the Southern Alberta Institute of Urology, Section of Urology, Department of Surgery, University of Calgary

Available to qualified applicants beginning July 1, 2015

\section{DESCRIPTION}

This is a one-year clinical fellowship. Upon completion, the fellow will be proficient in assessing and managing simple and complex presentations of incontinence, voiding dysfunction (neurogenic and non-neurogenic), pelvic organ prolapse, male stricture disease, female urologic conditions, and pelvic pain. Time will be spent in the clinic, urodynamics lab, cystoscopy suite and operating room. Technical skills will include performing and interpreting urodynamic studies (video and non-video), botulinum toxin injection, implantation of prosthetics, pelvic organ prolapse repairs (vaginal and laparoscopic approaches, including hysterectomy), other vaginal surgery (fistula repair, diverticulum excision, removal of vaginal mesh), urethroplasty, numerous surgical approaches to incontinence, cystectomy, augmentation cystoplasty, continent and incontinent urinary diversion, and ureteric reimplantation. Sacral nerve stimulation may also be available to the interested candidate. Completion and publication of clinical research projects is expected.

\section{CONTACT}

Kevin V. Carlson, MD, FRCSC, DABU (Fellowship Director) email: kevin.carlson@albertahealthservices.ca 